\title{
"Variable et mudable que no dura et se passa": El sufijo deverbal -ble en castellano medieval
}

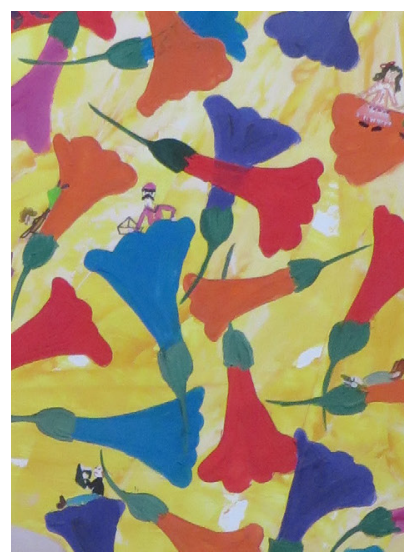

Andrzej Zieliński

Universidad Jaguelónica de Cracovia, Polonia

andrzej.zielinski@uj.edu.pl

Trabajo recibido el 6 de abril de 2021 y aprobado el 12 de agosto de 2021.

\section{Resumen}

El objetivo de este estudio es profundizar en el origen del sufijo deverbal -ble, considerado uno de los más productivos en la lengua española en la formación de adjetivos. Con la ayuda de los datos extraídos de textos latinos y castellanos intentaremos mostrar la trayectoria formal y discursiva de este elemento afijal antes de su consolidación en los albores del Renacimiento.

Palabras clave: sufijo -ble, latín cristiano, castellano medieval, modalidad

"Variable et mudable que no dura et se passa": The deverbal suffix -ble in Medieval Castilian

\begin{abstract}
The objective of this study is to explore the origin of the deverbal suffix -ble, considered one of the most productive in the Spanish language. Using the Corpus Diacrónico del Español (CORDE), the Corpus del español and the Library of Latin texts (BREPOLIS), the author has sought identify the formal and discursive trajectory of this affixal element before it became consolidated in the Spanish language at the dawn of the Renaissance.
\end{abstract}

Keywords: the -ble suffix, Christian Latin, Medieval Castilian, modality 


\section{"Variable et mudable que no dura et se passa": O sufixo deverbal -ble em espanhol medieval}

\section{Resumo}

O objetivo deste estudo é explorar a origem do sufixo deverbal -ble, considerado um dos mais produtivos da língua espanhola. Por meio do Corpus Diacrónico del Español (CORDE), do Corpus del español e da Biblioteca de textos latinos (BREPOLIS), o autor buscou identificar a trajetória formal e discursiva desse elemento afixal antes de se consolidar na língua espanhola nos primórdios de o Renascimento.

Palavras-chave: sufixo -ble, Latín Cristiano, Castelhano medieval, modalidade

\section{Introducción}

En las siguientes páginas nos proponemos mostrar el resultado de una investigación sobre el origen del sufijo deverbal -ble, uno de los más productivos en la formación adjetival (RAE y ASALE 2009, §7.10). Este sufijo de naturaleza alomórfica (-able para los verbos de la primera conjugación e -ible para los de la segunda y los de la tercera) está presente en todas las lenguas románicas: port. -vel, fr.-ble, it. -vole, cat. -vol y -ble, rum. -bil ${ }^{3}$ (Meyer-Lübke 1890-1906/1972 II, §408). Agregado a la base de los participios (RAE y ASALE 2009, §7.10a) ${ }^{4}$, manifiesta sus dos valores principales, herederos de los del sufijo latino del que proviene, -BILIS (Leumann 1917, 85): con verbos transitivos presenta una lectura pasiva y modal o potencial (verificable 'que puede ser verificado') y con intransitivos la activa (durable 'que dura', agradable 'que agrada'). A estos se añade la formación de los adjetivos que, a partir de bases nominales - procedimiento productivo en el lenguaje periodístico (RAE y ASALE 2009, §7.10p)—, designan cargos, como ministeriable, o dignidades, como rectorable, en los que presenta el significado de 'candidato a' (Rainer 1993, 433).

El motivo por el que abordamos este asunto radica en que el interés que en los últimos años ha despertado el funcionamiento semántico-sintáctico de -ble en español desde finales del siglo XX (Adelstein 2000; Fábregas 2011; Rainer 1999; Val Álvaro 1981) no lleva parejo un enfoque histórico. De hecho, no disponemos de un trabajo exhaustivo de carácter diacrónico que analice pormenorizadamente la vía de la entrada en la lengua española

1 En el título: Alfonso de Palencia, Universal vocabulario en latín y en romance, 1490, s. v. momentum.

2 Quiero expresar mi más profunda gratitud a los evaluadores anónimos por sus valiosos comentarios y sugerencias que contribuyeron a mejorar la versión final del presente estudio.

3 Sobre su evolución en portugués, véase Allen (1941, 75-77). Al parecer, en rumano actual este elemento afijal se introdujo de nuevo gracias a la rerromanización (Lüdtke 2011, 306). Por influencia del francés, lengua en la que el sufijo resulta muy productivo (Grevisse y Goosse 1932/2016, \$169), desde el siglo XVI el inglés dispone del sufijo -able (durable 'durable', available 'disponible') (Hoad 1986, s.v. -able) y el alemán de la variante -abel (akzeptabel 'aceptable', operabel 'operable').

4 Debido a la falta de espacio no vamos a examinar su formación irregular (romper-roto, pero rompible; imprimir-impreso, pero imprimible) o supletiva (potable). Para ello remitimos a Fábregas (2011), Lang (2002, 204-206), Miranda (1994, 143-144) o RAE-ASALE (2009, §§ 7.10.a-b), entre otros. 
de este sufijo que Val Álvaro (1981, 186-188) y Pharies (2002, s.v. -ble) califican de cultismo o latinismo, respectivamente, mientras Alvar y Pottier (1987, §309.2) se limitan a indicar su correspondiente étimo latino, -BILIS. No obstante, recientemente se ha publicado el estudio de Rifón (2021, 231233), quien determina la evolución de este elemento en español medieval sin entrar en detalles como su trayectoria antes de asentarse definitivamente en el código de la lengua española.

La excepción es el trabajo de García Pérez (2014), quien analiza la introducción de adjetivos denominales latinos como préstamos cultos (AMICA 'amiga' $\rightarrow$ AMICABILIS, de donde amigable, RATIONE 'razón' $\rightarrow$ RATIONABǏLIS, de donde razonable, términos documentados desde finales del siglo XIII). Remitimos a sus resultados para este aspecto de las formas en -ble, pero, como volveremos a indicar más adelante, en este artículo solo prestaremos atención a las formaciones patrimoniales.

Con la intención de llenar este evidente vacío rastreamos su evolución a través de tres corpus electrónicos (BREPOLIS, CORDE y Corpus del Español) desde el latín clásico hasta finales de la Edad Media, época en que el sufijo se asienta definitivamente en el código de la lengua española. A partir de ese momento experimenta una mayor vitalidad y se hace más productivo su empleo, lo que se comprueba con una clara ampliación de las bases verbales a las que a partir de entonces se une (Clavería Nadal 2019, 148).

La búsqueda por formas adjetivas con el sufijo -BILIS o -ble en los corpus electrónicos se ha realizado por archiformas y por centurias. Los datos cuantitativos en términos absolutos que se han obtenido en la investigación se distribuyen por tradiciones discursivas ${ }^{5}$ para ofrecer una imagen mucho más fidedigna de su trayectoria evolutiva. En lo que respecta a la lengua española, el cómputo realizado solo tiene en cuenta la formación adjetival patrimonial. Reiteramos que no se han tenido en cuenta, por tanto, los cultismos adjetivales analizados por García Pérez (2014), entre otros.

Este artículo consta de tres apartados: el primero se centra en la caracterización semántico-sintáctica del sufijo; en el segundo, con la ayuda de los datos extraídos de BREPOLIS, presentamos su comportamiento en latín clásico, latín vulgar y latín medieval; y en el tercero nos detenemos en sus primeras documentaciones en suelo ibérico, lo que permite observar su vía de penetración y el trayecto formal y discursivo que siguió. Termina el estudio con unas breves conclusiones.

5 "La lengua no es una entidad monolítica que se desarrolla como tal a lo largo del tiempo. Es un conjunto de variedades y tradiciones discursivas con evoluciones internas bien diferenciadas: una innovación se da, en general, en un texto determinado, en un texto que pertenece a una TD. A partir de ahí la innovación puede generalizarse en esa tradición, pero aún no es general en la lengua: hace falta la adopción de la innovación en otras tradiciones" (Kabatek 2005, 173). 


\section{Caracterización del sufijo -ble}

Como se ha dicho en el apartado anterior, los derivados adjetivales en -ble se forman a partir de las bases verbales tanto transitivas (lavar $\rightarrow$ lavable) como intransitivas (durar $\rightarrow$ durable), siendo el primer patrón el más recurrente en la lengua española (RAE-ASALE 2009, §7.10i).

En su formación, los adjetivos en -ble heredan la estructura argumental de la base $^{6}$ (Adelstein 2000, 14-18; Rainer 1999, §70.2.2.2; RAE-ASALE 2009, $\S 7.10 \mathrm{i}$, entre otros), de suerte que el argumento interno que supone el empleo predicativo del verbo base, de carácter transitivo con sujeto agenti$\mathrm{vo}^{7}$ (Pedro atribuye la obra a este autor, Juan construye la casa, El gobierno extrae impuestos de la nómina, etc.) se exterioriza en la formación adjetival con el papel de tema (la obra atribuible a este autor, la casa construible o los impuestos extraíbles de la nómina) (Rainer 1993, 430). De este modo, los adjetivos creados sobre una base verbal transitiva admiten la presencia de un complemento agente (la nota verificable por el alumnado) o de un complemento circunstancial (el material transportable en un coche; la montaña visible desde lejos; el tejido lavable con lejía (Rainer 1993, 430).

Desde una perspectiva semántico-sintáctica, llama la atención su función estrictamente predicativa (Bosque 2013, 46-48), en el sentido de que denotan una propiedad externa otorgada por el juicio del emisor, razón por la cual Adelstein $(2000,14)$ le atribuye siempre un carácter eventivo, independientemente de la base adjetiva (vivible, verificable), lo que implica que, en vez de identificar una característica inalienable del objeto designado (cf. mesa redonda, ventana sucia, flor roja), codifican la actitud —como elemento argumental adicional- de cómo percibe el emisor el objeto dentro de la escala de lo posible de la realización del evento, de carácter "ficticio" (Arias Abellán 2001, 680) porque todavía no se ha efectuado (agua bebible 'que se puede beber', casa edificable 'que se puede edificar', etc.) ${ }^{8}$. De ello puede deducirse que su lectura es, ante todo, de carácter modal y que la actitud del emisor se desenvuelve entre las dos nociones básicas de la lógica tradicional: posibilidad y necesidad (Lyons 1977, 787).

En este orden de cosas, como en la lengua española distinguimos tres tipos de modalidad fundamentales: (i) la modalidad dinámica, regida por leyes de naturaleza; (ii) la modalidad deóntica, regida por leyes sociales; y (iii) la modalidad epistémica, regida por leyes de lógica y razonamiento (Espinosa Elorza y Zieliński 2021, 21-22; Zieliński y Espinosa Elorza 2018, 20-35), cabe suponer que esta tripartición se encuentre también en

$6 \mathrm{Al}$ heredar la estructura argumental, esta debe ser, al menos, monovalente (durar $\rightarrow$ durable), de modo que los verbos impersonales rechazan la derivación con el sufijo -ble (llover $\rightarrow$ *Ilovible, anochecer $\rightarrow$ *anochecible).

7 Aunque requiera un análisis más exhaustivo que, debido a la extensión limitada del trabajo, no podemos abordar en este estudio, creemos que la aceptación de la formación adjetival con el sufijo -ble se lleva a cabo únicamente con aquellos predicados ubicados en la posición superior de la escala de transitividad, que, en consonancia con la hipótesis de transitividad de Hopper y Thomson (1980, 252-253), se elabora a base de los parámetros graduables de agentividad, telicidad, puntualidad o voluntariedad, entre otros. Al aplicarla a los adjetivos que nos interesan, entenderemos por qué tener - ubicado en el lugar más bajo de la escala-carece del adjetivo en -ble ("tenible), mientras que conocer, creer, sufrir - situados en una posición superior en la misma, debido a su carácter voluntario y dinámico- los presentan: conocible, creíble o sufrible.

8 Tal vez, por ello Cabré (2002, \$6.2.4.3.) le asigna un carácter incoativo. 
la interpretación de los adjetivos deverbales en -ble. En efecto, al igual que ocurre con el verbo modal poder, los adjetivos en -ble presentan un carácter sumamente polisémico; esto es, permiten, en principio, codificar los tres valores modales según la situación contextual y la naturaleza

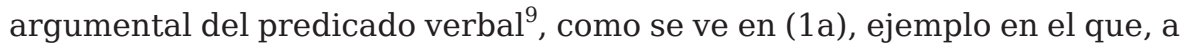
falta del contexto específico que caracteriza una definición lexicográfica, la conuersaçión tratable puede ser interpretada en términos de la modalidad dinámica, aludiendo así a la condición circunstancial interna del sustantivo conversación, que, a ojos del emisor dispone de la capacidad de ser tratada de manera mansa, o bien en términos de la modalidad deóntica, mediante la cual la condición circunstancial de tratar la conversación dócilmente se ve impuesta por normas sociales de cortesía que lo exigen.

No obstante, la presencia implícita o explícita del agente produce que la interpretación modal de los adjetivos deverbales esté siempre sujeta a la posibilidad externa -o sea, el permiso otorgado por una fuerza externa, regida por leyes sociales - o interna, regida por leyes de naturaleza, como la aptitud de hacer algo, inherentemente vinculada al sujeto - (Zieliński y Espinosa Elorza 2018, 25-32). Por ello, frente a la opinión de Val Álvaro $(1981,195)$, creemos que la ambigüedad puede asociarse solo al ámbito de la posibilidad radical con dos valores esenciales: 'posibilidad dinámica'capacidad- (1b-1c) y 'posibilidad deóntica' - permiso- (1d-e).

Por otra parte, podríamos pensar que, dada la ausencia del sujeto agentivo en los predicados intransitivos, sus correspondientes adjetivos deverbales con -ble se inscribirían satisfactoriamente en la lectura epistémica (película agradable? 'que tal vez agrada/agrade', bienes durables? 'que tal vez duran/ duren'). Sin embargo, muchos de ellos entran en español como cultismos (RAE-ASALE 2009, §7.10d) y, si alguna vez lograron la lectura epistémica, se vieron desprovistos de ella en la época clásica (vid. § 3). De hecho, en sus respectivas definiciones lexicográficas proporcionadas en el $D L E$ (online, s.vv. agradable, durable) aparecen sin elemento modal: 'que agrada' o 'que dura'.

Y, por último, el significado de 'posibilidad deóntica' de algunos adjetivos (aconsejable, condenable, despreciable, etc.) puede pasar contextualmente al de 'necesidad deóntica' por inferencia (1f-g).

(1) a. lenitas. tis. es la mesma mansedumbre o conuersaçion tratable (Palencia, Universal vocabulario en latín y en romance, 1490, CORDE).

b. su letra en sí no era buena ni tan legible como era dulcísima, elegante, graciosa y bien ordenada en todo lo que contenia (Fernández de Oviedo, La vida del Gran Capitán, ca. 1497-1515, CORDE).

\footnotetext{
9 "Hay adjetivos como absorbible, coagulable, digerible o evaporable que no admiten el sentido de 'permiso'. Son adjetivos formados sobre verbos cuya estructura de valencias semánticas excluye lógicamente la presencia de un causativo personal. De otra, los adjetivos derivados de verbos con objeto del tipo "effectum" no permiten la interpretación de 'capacidad': edificable, ejecutable, elaborable, fabricable, inventable, realizable. Ello es natural dado que los términos de base se refieren, no a acciones que afectan o se aplican a un objeto ("affectum"), sino a acciones que llevan consigo la actualización del mismo. Consecuentemente, el desarrollo del proceso implicado por el derivado no puede estar determinado por características inherentes al objeto" (Val Álvaro 1981, 195-196).
} 
c. El primer çirculo es arctico inhabitable por frialdad (Palencia, Universal vocabulario en latín y en romance, 1490, CORDE).

d. Y acerca deste artículo, según la doctrina de los filósofos y sabios antigos, el prudente político deve ante todas las cosas tomar un fundamento y conclusión inviolable que en esta parte ponen los filósofos (Sánchez de Arévalo, Suma de la política 1454-1457, CORDE).

e. hablando con uno, usamos del número de muchos, diziendo vos venistes por dezir tú veniste, por que, como dize Donato en su Barbarjsmo este es vicio no tolerable: el cual los griegos Ilamen solecismo (Nebrija, Gramática sobre la lengua castellana, 1492/2011: 120).

f. es muy laudable por que el calor natural conforta a buena digestion el cuerpo apareja (Estéfano de Sevilla, Visita y consejo de médicos, ca.1400, CORDE).

g. Levante la Fama su boz ineffable, / por que los fechos que son al presente / vayan de gente sabidos en gente / olvido non prive lo que es memorable (De Mena, Labirinto de Fortuna, ca. 1444, CORDE).

Como precisa Rainer (1999, §70.2.2.3), “la plausibilidad de esta inferencia depende de la semántica del verbo base: una película solo puede (o debería) recibir el óscar si se lo merece, en tanto que el hecho de que una radio sea extraíble no justifica la inferencia de que se debe extraer".

\section{Comportamiento de -BILIS en latín clásico, latín vulgar y latín medieval}

Los valores del sufijo modal español -ble son una prolongación de los del latín clásico -BILIS, que presentaba una variante alomórfica -ILIS, propia de las bases verbales en - $e$ y -o (AGILIS 'que se puede manejar') o con vocal larga (HABILIS 'que se puede llevar') (Dell' Oro 2019, 200). Se agregaba a la raíz verbal (AMABILIS 'que se puede amar'), a los participios de los verbos de la tercera conjugación (INCREDIBILIS 'que no puede creer', 'incrédulo') e incluso a bases nominales (LACRIMABILIS 'digno de llanto, de lágrimas') a partir de la época tardía.

Disponía de tres valores, estrechamente vinculados (Benveniste 1935, 202206): por una parte, tenía el instrumental (2a) -asociado metonímicamente con la causa- (TERRIBILIS 'a través del cual causa terror', HORRIBILIS 'mediante el cual provoca temblor'), que Hanssen $(1889,281)$ y Leumann $(1917,84)$ consideran el más antiguo y origen de los otros dos; por otra parte, el de 'posibilidad radical' en la interpretación pasiva con verbos transitivos ( $2 \mathrm{~b}-\mathrm{c})$ y en la activa con los intransitivos, sin que esté necesariamente implicado lo modal (2d-e).

(2) a. Annus horribilis 'año terrible' [lit. Año por los terrores causados], annus mirabilis 'año de los milagros' [lit. Año por los milagros']. 
b. Me miseram, quod amor non est medicabilis herbis! (Ovidio Nasón, Epistulae Heroidum, 5, 140, BREPOLIS) ‘Ay de mí, mísero, que el amor no es medicable con ninguna hierba'.

c. aeque laudabilis virtus est (Séneca, Epistulae morales ad Lucilium, 66, 22, BREPOLIS) 'La virtud es tan loable'.

d. Quod caret alterna requie, durabile non est (Ovidio Nasón, Epistulae Heroidum, 4, 89, BREPOLIS) 'Aquello que carece del descanso alternativo no puede durar/no dura'.

e. nimis bella es atque amabilis, et si hoc meum esset, numquam me oraresquin darem (Plauto, Asinaria, 674, BREPOLIS) 'eres demasiado bella y digna de ser amada y, si esto fuera mío, nunca me lo pedirías sin que te lo diera'.

A la lectura pasiva, la más frecuente en el latín clásico, Leumann $(1977, \S 312)$ asigna el concepto de Wünschbarkeit 'deseabilidad', en el sentido de que modaliza el objeto designado en términos de posibilidad, que, según la naturaleza del predicado de la base, puede matizarse con la idea de 'deseo' (AMABILIS 'digno de ser amado') — dentro del mundo dinámico- y con la de 'obligación' - propia de la lectura deóntica(EXCRUCIABILIS 'que debe ser torturado'). Por su parte, Arias Abellán $(2001,681)$ lo califica de "fictivo" - porque el evento asignado todavía no se ha realizado- junto al sufijo -NDUS, con la diferencia de que -BILIS añade la idea de 'posibilidad' y -NDUS la de 'necesidad' de la realización de la acción que recae en el objeto-paciente, de ahí la fuerte carga moral y ética que implica su empleo (Hanssen 1889, 275) y que determinará su uso en épocas posteriores.

A juzgar por los datos hallados, la productividad de -BILIS resulta marginal en el llamado latín clásico en comparación con su empleo en épocas posteriores (vid. diagrama I, más abajo). De hecho, como nos hace notar Cooper (1895/1975, §29),durante esta época su empleo se ciñe, por lo general, a adjetivos creados en la época arcaica.

Para nuestro estudio resulta esencial el legado de Plauto (Arias Abellán 1991, 124-128), quien lo pone a menudo en boca de personajes pertenecientes a la clase social baja, como Léonidas, esclavo de Demétero, en la comedia Asinaria (2d). De ello puede deducirse que su empleo estuvo relacionado con el registro oral (de ahí su poca frecuencia en los autores clásicos), como prueba su rica documentación en las inscripciones pompeyanas (Väänänen 1959, 99) o en los autores de procedencia africana (Cooper 1895/1975,§29) ${ }^{10}$. El carácter popular —unido a su carga semántica de "moralische Möglichkeit" 'posibilidad moral', concepto reivindicado por Hanssen $(1889,275)$ - determina, a su vez, que caiga en un terreno bien abonado: el de los primeros cristianos, quienes, con su afán de adoctrinar a los estratos más bajos de la sociedad del imperio, optan por un lenguaje sencillo pero metafórico (Blaise 1955,

10 Obsérvese que también está registrado en el Appendix Probi. Aunque sirva para ejemplificar un fenómeno fonético (TOLERABILIS NON TOLERAVILIS, ejemplo tomado de la ed. de Díaz Díaz 1962, 53), su presencia en este listado pone de manifiesto el carácter popular del sufijo. 
12-14; Löfstedt 1959, 70-71). Su uso a partir de entonces se relaciona e identifica discursivamente con el latín cristiano (Grandgent 1907/2009, §39), como prueba su alta frecuencia en la Vulgata, repleta de adjetivos con -BILIS que, aparte de modalizar el contenido nominal (3a), puede servir como procedimiento de formación de palabras compuestas traducidas del griego (Blaise 1955: 16), como se ve en (3b), ejemplo en el que al sintagma nominal latino Deo odibiles le corresponde el adjetivo

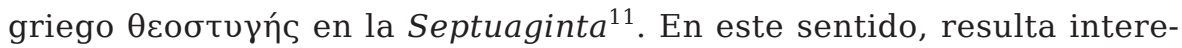
sante observar que sus traducciones al castellano en el códice E8, de la primera mitad del siglo XIII,resaltan perfectamente esta dicotomía (3a') y $\left(3 b^{\prime}\right)$. Nótese que únicamente se traducen con el adjetivo español en -ble los usos de carácter modal ${ }^{12}$.

(3) a. qui est imago Dei invisibilis primogenitus omnis creaturae (Ep. Pauli ad Colossenses, $1,15)$.

a.' el que es ymagen del non uisible dios engendrado primero de toda creatura (Enrique-Arias y Pueyo Mena: online, Biblia medieval).

b. detractores Deo odibiles contumeliosos superbos elatos inventores malorum parentibus non oboedientes (Ep. Pauli ad Romanos, 1, 30).

b'. Maldizientes. aborrecidos de Dios. denostadores. soberuios. orgullosos. assacadores de males no obedecientes a sos padres (Enrique-Arias y Pueyo Mena: online, Biblia medieval).

Sea como fuere, su pronta propensión al latín cristiano determinó no solo su mantenimiento, sino también su alta frecuencia relativa en latín tardío ${ }^{13}$. En efecto, si observamos el diagrama 1, podemos comprobar que su frecuencia de empleo - en términos absolutos- se dispara a partir del Edicto de Tesalónica, del año 380, de suerte que una centuria más tarde su número llega a multiplicarse por cien en comparación con sus empleos anteriores.

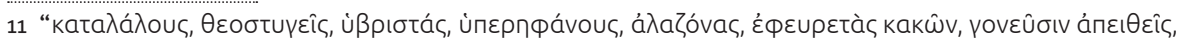
áouvétouc" (Ep. Pauli ad Romanos, 1, 30, Perseus).

12 Dada la época de mayor extensión de empleo y su evidente inclinación al registro discursivo del latín cristiano, resulta muy tentadora la idea de percibir la influencia del sufijo modal griego -ı nominal, con usos muy parecidos a los que presentaba -BILIS (Dell'Oro 2019, 201-204). No obstante, nuestra comparación de dos versiones del Nuevo Testamento no proporciona pistas inequívocas, dado que los pasajes con -BILIS en la Vulgata no siempre coinciden con su empleo en la Septuaginta.

13 La misma suerte se ha observado en el sufijo adjetival superlativo -ISSIMUS, que, aunque desaparece del latín vulgar (Väänänen 1985, \$262), se conservó con éxito en latín cristiano, fuente de la que beben los escasos ejemplos del castellano medieval (Zieliński 2013; 2015). 


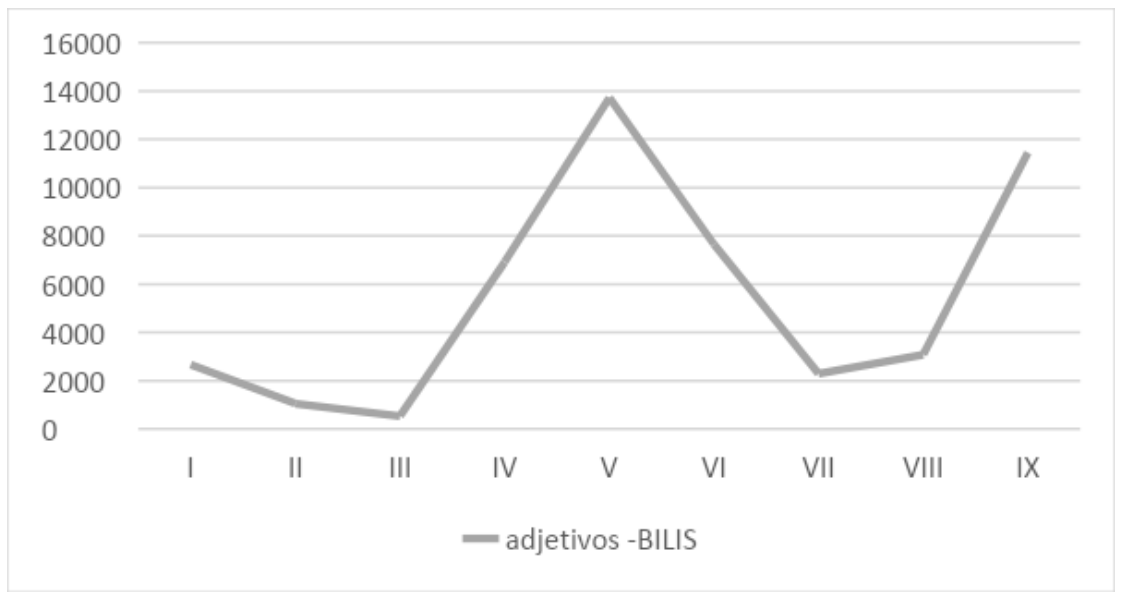

Diagrama 1. Frecuencia absoluta de los adjetivos en -BILIS en latín clásico y medieval (fuente: BREPOLIS).

En los siglos posteriores esta tendencia al alza se mantiene de manera palmaria $^{14}$, lo que implica su extensión discursiva hasta convertirse en un afijo sumamente productivo en latín medieval, como demuestra, entre otros casos, la sustantivación en el lenguaje jurídico del adjetivo MŎBILIS a pa0rtir de [RES] MŎBILIS, de donde se obtiene mueble 'cosa que se puede mover' (Corominas y Pascual 1980, s.v. mover).

Si bien se mantiene en textos de carácter religioso (4a), a partir del siglo VI no es raro hallarlo en los géneros historiográfico (4b) y, en menor medida, epistolar (4c).

(4) a. Prima et inmutabili constitutione decretum est, ut cum mitrupulitanus fratres uel conprouincialis suos ad concilium aut ad ordinationem cuiuscumque consacerdotis credederit euocandus, nisi causa taedii euedentis exteterit, nullus excusit. (Anónimo, Concilium Epaonense, 24, 76, s. VI, BREPOLIS) 'En la primera e inmutable constitución se decretó que cuando el arzobispo o el obispo [envía] a sus hermanos al concilio o a la ordenación de cualquier sacerdote a la que hubiere creído ser convocado, no se le disculpa si no por causa de un evidente impedimento'.

b. Regi autem saeculorum inmortali et invisibili(Gregorio de Tours, Historiarum libri X, 46 40, s. VI, BREPOLIS) 'al Rey de los siglos inmortal e invisible'.

c. Sed tolerabilius est antiquiorem fratrem quam novum et puerum tolerare (Gregorio Magno, Registrum epistularum, 9, 20, 40, s. VII, BREPOLIS) 'pero es más tolerable soportar al fraile más antiguo que al reciente y joven'.

Cabe, por lo tanto, suponer que los primeros ejemplos castellanos se relacionan con las tradiciones discursivas del latín medieval en las que el empleo del -BILIS abundaba, en consonancia con el planteamiento de Barra Jover $(2010,64)$ sobre las fuertes interferencias del latín medieval en las lenguas románicas. 


\section{Primeras manifestaciones en castellano}

Aunque Menéndez Pidal (1929, §45.5) encuentra en los diplomas notariales leoneses del siglo XI algún ejemplo, como ARATIBILE > aradeble, aradívile 'que puede ser arado', este, en realidad, refleja un uso latinizante del término romanceado por el copista. Tampoco el sufijo está registrado en el Cantar de Mío Cid. Los primeros ejemplos nos llevan a la primera mitad del siglo XIII, a la Fazienda de Ultramar, con pasajes que aluden claramente a la Biblia (5a-b), y al legado de Berceo, de temática evidentemente religiosa (5b-c). Son, por lo tanto, los textos de carácter religioso los que permiten el paso al castellano de este elemento derivativo. De hecho, los primeros adjetivos formados con -ble a los que hemos tenido acceso son claramente préstamos del latín (Pharies 2002, s.v. -ble), que aparecen en singular: durable < DURABILLE 'que dura', perdurable < PERDURABILE 'que dura mucho tiempo', estable < STABILE 'que se mantiene de pie (y de ahí firme)' $\mathrm{y}$, empleados al final del verso alejandrino, sirven para mantener no solo el cómputo silábico, sino también la rima consonante, indispensable en el mester de clerecía.

Dada la clara temática moralizadora de estas obras, no debe sorprendernos que predominen los adjetivos con valor activo, ya que las propiedades eventivas que se atribuyen a los sujetos u objetos divinos son dogmas cristianos (regno durable, salud perdurable, paz estable, con clara referencia al paraíso celestial o a las cualidades de la Gloriosa), que no se someten al juicio de los hablantes (5a-c). Los pocos adjetivos que se utilizan dentro del mundo profano (regno deseable o sotileza mirable) consiguen una lectura pasiva inscrita en la necesidad deóntica (mirable < MIRABILE 'que debe ser admirado'; deseable 'que debe/digno de ser deseado' < DESIDERABILE), en la que una fuerza externa que empuja a los sujetos agentivos a la realización de eventos se relaciona con leyes sociales.

(5) a. su regno durable sera e todos los reyes a el serviran e obedeçran. E yo, Daniel, mios cuedados mucho torbaron e myo color se demudo sobre mi, e la palabra en mio coraçon guardé (Almerich, Fazienda de Ultramar, ca. 1200, CORDE).

b. ca es su santo nombre durable, non mortal (Berceo, Del sacrificio de la misa, ca. 1228-1246, CORDE).

c. Vida da, que non fin, e saludperdurable, claridat más de sol / Claridad maior de sol, firme paz e estable / Ligereza mas de viento, sotileza mirable /Tal regno de tan buen reyes muchodeseable(Berceo, Loores de Nuestra Señora, ca. 1236-46, CORDE).

Con todo, en la misma centuria también se registra en la prosa historiográfica de Alfonso X en los Castigos de Sancho IV, de género sapiencial, sin que esta extensión discursiva lleve consigo cambios sustanciales en su empleo. Nótese que todos los ejemplos hallados — salvo el lexicalizado noble < NOBILE, derivado de NOSCERE 'saber, conocer', omnipresente en la obra- aluden siempre a un sujeto u objeto divino, que no está al alcance del emisor (6a-d) —de ahí que no se someta a la modalización-, mientras que los objetos considerados profanos (enfermedad, ley humana) se ponen en 
tela de juicio por parte del emisor y, por consiguiente, resultan modalizados a través del verbo modal poder en la estructura de pasiva refleja (6e) o de pasiva analítica (6f), como queda perfectamente patente en la traducción de los pasajes bíblicos en la tercera parte de la General Estoria (6g-i). Obsérvese que, si el referente al que alude el adjetivo latino en -BILIS es profano, se opta por la selección de la construcción perifrástica con poder (6g-h) y, si es divino (spiritus), se mantiene (6i).

(6) a. Et la su alma sea heredada con los sus santos fieles en la gloria de su sancto Reyno durable amen (Anónimo, Estoria de Espanna III, ca. 1284, CORDE).

b. E en el vo ferio nuestro sennor dios all emperador Costantin de grand ferida de muert. ca fue encendido del fuego perdurable\& ardie seyendo uiuo (Alfonso X, Estoria de Espanna I, ca. 1270, CORDE).

c. los echamos dent. por que uos guardedes de aorar sos dios \& los sos ydolos. que non son otra cosa si non; uanidat. \& suziedat \& pesar de dios \& muerte durable. de los que los siguen (Alfonso X, General Estoria II, ca. 1275, CORDE).

d. Ca njnguno non teme sy non quando ymagina algund peligro njn ha osadia sy non quando acomete alguna cosa espantable o peligrosa (Anónimo, Castigos, ca 1293, CORDE).

e. Et mientre la enfermedat parescie que se podrie melezinar. maguer que tenie encubierta de yuso tanto enfermedat. que despues non prestaua. trauaiauan se los onbres de acorrer con fisica (Alfonso X, General Estoria II, ca. 1275, CORDE).

f. por ende dixol. Porque esta ley de no fablar que te tu mismo as puesta non puede seer quebrantada; (Alfonso X, Estoria de Espanna I, ca. 1270, CORDE).

g. et cor regum inscrutabile e el coraçon de los reyes non son cosas que escodriñar se puedan (Alfonso $X$, General Estoria, III, Proverbios, XXV, 3, ca. 1280, CORDE).

h. nec deficias (quasi onus importabile) cum ab eo corriperis nin fallezcas como de carga que non se puede levar quando te él castiga (Alfonso X, General Estoria, III, Proverbios, III, 1, ca. 128o, CORDE).

i. qui capiat omnes spiritus intellegibiles quien cabe todos los espíritus entendibles (que se pueden entender) (Alfonso X, General Estoria, III, Sabiduría, VII, 23, ca. 128o, CORDE).

Su frecuencia de empleo a partir de entonces va en claro aumento. A juzgar por los datos que se exponen en el diagrama 2, su número -en términos absolutos- se multiplica por dos en tan solo una centuria. También los datos cuantitativos elaborados por Rifón $(2021,232)$ apuntan a una clara tendencia en alza desde finales del trescientos, lo cual supone su extensión a nivel formal y discursivo hasta el triunfo definitivo a partir de finales del medievo. 




Diagrama 2. Frecuencia absoluta de los adjetivos en -ble en castellano medieval (fuente: Corpus del español).

Si bien su empleo prevalece en textos de temática religiosa e histórica que beben de fuentes bíblicas o de otros textos latinos (7a-b), a lo largo del siglo XIV su peso discursivo se centra en textos de carácter didáctico (7c-f), cambio que coincide con una restricción semántica, ya que este procedimiento de derivación adjetival se ciñe a casos con sentido pasivo, como donable 'que puede darse', aborresçible 'que puede ser aborrecido' o corrutible 'que puede ser corrompido', único ejemplo registrado en El Conde Lucanor, préstamo desde el latín CORRUPTIBILIS (Val Álvaro 1981, 188).

Desde una perspectiva morfosintáctica, resulta interesante observar su extensión a partir de su uso como adjetivo pospuesto al sustantivo - siempre de carácter pasivo- hasta alcanzar la función de atributo ${ }^{15}$ (7f), paso previo a su adverbialización a través de -mente desde la segunda mitad del siglo XIII (7g-h) en el mismo tipo de textos.

(7) a. La difiniçión de la fortaleza es ésta: estableza del coraçón non movibleentre las cosas adversarias de trabajos e peligros (Cuéllar, Catecismo, 1325, CORDE).

b. Mas que apres muchos dias se esdeuedeien que aquel lugar venerable seria menospreciado et que serien posados aqui ministres, no por meritos de vida, mas por intercesion de senyores terrenales (Fernández de Heredia, Traducción de Breviarium ab urbe condita, 1377-1399, CORDE).

c. ca el cuerpo es cosa corrutible et el alma, cosa duradera (Juan Manuel, El Conde Lucanor, 1325-1335, CORDE).

d. Ffue un ombre en Apulia muy aborresçible a Dios e a la Virgen Maria e muy gracioso a los señores temporales que tenia (Sánchez de Vercial, Libro de los exemplos por A. B. C., ca. 1400, CORDE).

e. De talla muy apuesta e de gesto amorosa, / loçana, doñeguil, plazentera, fermosa,/ cortés e mesurada, falaguera, donosa, / graçiosa e donable, amor en toda cosa (Ruiz, Libro de buen amor, 1330-1343, CORDE).

15 A este respecto señala Bosque (1989: 139) que "la lengua concibe propiedades de los individuos como modos de ser [...] (y, por consiguiente) las cualidades de los objetos vienen a ser conceptualizadas como las formas en que se muestran o en que aparecen". 
f. El mouimiento o treballo antes de yantar mueue la calentura del stomago, mas el andar apres yantar es nozible, porque en el treballo aualla la uianda no cozida a la mas baxa part del stomago, et despues engendrados en los ençerramientos et otros males Fernández de Heredia, De secreto secretorum, 1376-1392, CORDE).

g. E el florester los acojo honorable mente (Anónimo, Cuento de don Tristán de Leonís, ca. finales del siglo XIII, CORDE).

h. Pues es causa que la vida se passe graciosa y apaziblemente: y cada vno pueda conella exercitar su oficio (Anónimo, Sevillana medicina de Juan de Aviñón; ca 1381-1418, CORDE).

A partir de principios del siglo XV el empleo de -ble despunta y consolida su funcionamiento. Su vitalidad se comprueba en un gran número de ejemplos creados a base de verbos patrimoniales en diferentes géneros discursivos, tanto con lectura pasiva (8a) como con lectura activa (8b). Dada la época, podría pensarse que la tendencia latinizante que caracteriza la lengua en los albores del Renacimiento (Lapesa 1981: §70) habría podido contribuir a su consolidación. Sin embargo, en los autores prerrenacentistas que beben de las fuentes clásicas su empleo resulta marginal y, en todo caso, se trata de cultismos léxicos (favorable < FAVORABILE, ineffable < INEFFABĬLE, memorable < MEMORABĬLE) (8c.) En la Gramática sobre la lengua castellana de Nebrija, el sufijo aparece tan solo en adjetivos deverbales de carácter deóntico (8d-f), como incomportable ${ }^{16}$ 'intolerable' o tolerable, a través de los cuales el primer gramático castellano condena mayoritariamente vicios de lengua ( $8 \mathrm{~d}-\mathrm{e})$ o bien señala en términos deónticos que algo es digno de atención o de cuidado (8f) ${ }^{17}$.

(8) a. la mar se pinta con tres dientes que es las tres propiedades del agua que es nadable fluxible \& bebible (Gómez de Zamora, Morales de Ovidio, ca. 1452, CORDE).

b. [...] por aquel amor entrañable que en ti conozco (Rodríguez de Montalvo, Amadís de Gaula,1482-1492, CORDE).

c. Tú, Caliope, me sey favorabledándome alas de don virtuoso, / y por que discurra por donde non oso, / conbida mi lengua con algo que fable; / levante la Fama su boz ineffable, / por que los fechos que son al presente / vayan de gente sabidos en gente / olvido non prive lo que es memorable (Juan de Mena, Laberinto de Fortuna, 1444, CORDE).

d. (s)[S]olecismo como diximos es vicio incomportableenla juntura delas partes dela oracion (Nebrija, Gramática sobre la lengua castellana, 1492/2011: 130).

e. I mucho menos tolerable seria si dixiesses "vuestra merced es bueno»: por que no concuerdan en genero el adjectivo con el substantivo (Nebrija, Gramática sobre la lengua castellana, 1492/2011:120).

$16 \mathrm{Al}$ parecer, se trata del calco léxico del latín medieval INCOMPORTABILIS, muy frecuente en los tratados medievales, a juzgar por nuestra búsqueda en BREPOLIS.

17 No hemos podido comprobar la existencia del adjetivo probable en la gramática de Nebrija, que uno de los evaluadores anónimos parece encontrar, ni en la búsqueda en el CORDE ni en la edición de Carmen Lozano Guillén (Madrid: Real Academia Española, 2011) que manejamos en este estudio. 
f. Coplas llaman nuestros poetas un rodeo \& aiuntamiento de versos en que se coge alguna notable sentencia (Nebrija, Gramática sobre la lengua castellana, 1492/2011:73).

No se puede descartar que su vitalidad y productividad, observables en los textos castellanos a finales de la Edad Media,se vieran favorecidas por la rivalidad con otros sufijos adjetivales deverbales, como demostró Fleischman (1978) con respecto al desarrollo del sufijo -azgo. En opinión de Val Álvaro (1981, 188-189), se trata, sobre todo, de la influencia de los sufijos adjetivales -ivo y -dero, de significado parecido, con los que compite -ble (cf. afectivo vs. afectable o duradero vs. durable).

\section{Conclusiones}

A pesar de la irrefutable semejanza formal y semántica que comparte el sufijo español -ble con su étimo latino -BILIS, su trayectoria resulta mucho más compleja de lo que se había creído hasta ahora.

En primer lugar, en latín clásico su empleo estuvo ligado a los textos de proximidad comunicativa y posteriormente, con la imposición del cristianismo, su empleo se vuelve muy frecuente en los textos de carácter religioso. A juzgar por su primera documentación en Berceo o en los pasajes bíblicos de la Fazienda de Ultramar, se puede afirmar que esa es la vía de entrada de los primeros adjetivos en castellano como cultismos léxicos.

En segundo lugar, los textos del siglo XIII presentan una clara dicotomía semántica: los adjetivos en -ble de carácter activo aluden normalmente a una propiedad eventiva divina que no puede ser modalizada, mientras que la lectura pasiva y modal se registra únicamente en referencia a los objetos terrenales. A partir del siglo XIV, aunque predomine en los textos de carácter religioso, se observa su introducción en el género didáctico, en el que experimenta extensiones de carácter morfosintáctico y semántico.

Finalmente, a partir del siglo XV se consolida y se mantiene con vitalidad hasta hoy para la formación de nuevos adjetivos. 


\section{Q Bibliografía}

》 Adelstein, Andreína. 2000. “Gramática y representación lexicográfica: los derivados en -ble”. Filología XXXIII: 7-29.

"Allen, Joseph. 1941. "Portuguese word-formation with suffixes". Language 17, 2: 3-143.

» Alvar, Manuel, y Bernard Pottier. 1987. Morfología histórica del español. Madrid: Gredos.

» Arias Abellán, María del Carmen. 1991. "Die deverbalen Adjektive auf «-bilis» in den Werken des Plautus". Glotta 69: 124-36.

"Arias Abellán, María del Carmen. 2001. "Análisis de la modalidad en los adjetivos latinos deverbativos". Habis 32: 677-84.

" Barra Jover, Mario. 2010. “Cómo vive una lengua 'muerta’: El peso del latín medieval en la evolución del romance”. En Modelos latinos en la Castilla medieval, editado por Mónica Castillo Lluch y Marta López Izquierdo, 63-80. Madrid/Frankfurt am Main: Iberoamericana/Vervuert.

»Benveniste, Émile. 1935. Origines de la formation des noms en Indo-Européen. Paris: Librairie Adrien-Maisonneuve.

"Blaise, Albert. 1955. Manuel du latin chrétien. Strasbourg: Le Latin Chrétien.

"Bosque, Ignacio. 1989. Las categorías gramaticales: relaciones y diferencias. Madrid: Síntesis.

" Bosque, Ignacio. 2013. "Predicados que hacen de argumentos". En Lingüística-retórica-teoría de la literatura: trabajos ofrecidos en memoria del profesor José Antonio Mayoral, editado por María Jesús Fernández Leborans y Luis Martínez Falero, 43-56. Madrid: Arco Libros.

" BREPOLIS: Brepolis Publishers (online), Library of Latin texts. <http://www.brepolis. net/> [07/2021].

" Cabré, María Teresa. 2002. "La derivació". En La Gramàtica del català contemporani, editado por Joan Solà Cortassa et al., vol. I: 731-75. Barcelona: Editorial Empúries.

»Clavería Nadal, Gloria. 2019. "Historia del léxico". En Manual de lingüística española, editado por Emilio Ridruejo, 133-66. Berlin/Boston: De Gruyter.

"Cooper, Frederic. 1895/1975. Word formation in the Roman Sermo Plebeius. Hildesheim/ New York: Georg OlmsVerlag.

》CORDE: Real Academia Española (online), Corpus diacrónico del español. <http://corpus. rae.es/cordenet.html> [08/2021].

"Corominas, Joan y José Antonio Pascual. 1980-1991. Diccionario crítico etimológico castellano e hispánico, 6 vols. Madrid: Gredos.

»Corpus del español: Davies, Mark (online), Corpus del español. <https://www.corpusdelespanol.org/> [08/2021].

"Dell'Oro, Francesca. 2019. “L'expression de la modalité par des adjectifs: une comparai-

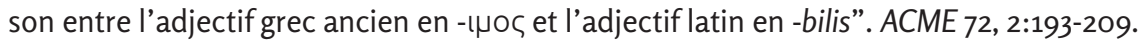

» Díaz Díaz, Manuel. 1962. Antología del latín vulgar. Madrid: Gredos.

» DLE: RAE y ASALE (online). Diccionario de la lengua española. https://dle.rae.es/. Fecha de consulta, agosto de 2021. 
»Enrique-Arias,Andrés y Francisco Javier Pueyo Meya (online), Biblia medieval, http://corpus.bibliamedieval.es/. Fecha de consulta, agosto de 2021.

»Espinosa Elorza, Rosa María y Andrzej Zieliński. 2021. "Los cruces de caminos entre la modalidad, la aspectualidad y la temporalidad en la historia del español”. En La interconexión de las categorías semántico-funcionales en algunas variedades del español. Estudios sobre la interacción de la temporalidad, aspectualidad, modalidad y evidencialidad, editado por Verónica Böhn y Anja Hennemann, 21-38. Berlin: Peter Lang.

"Fábregas, Antonio. 2011. "Propiedades sintácticas y alomorfía: alternancias con el sufijo -ble”. En Teoría morfológica y morfología del español, editado por José Pazó Espinosa et al., 59-88. Madrid: Ediciones de la Universidad Autónoma de Madrid.

" Fleischman,Suzanne. 1978. "Factores operantes en la historia de un sufijo: el caso de "azgo»". En Estudios ofrecidos a Emilio Alarcos Llorach, editado por José Luis García Arias et al., Vol. III: 75-85. Oviedo: Universidad de Oviedo.

》 García Pérez, Rafael. 2014. "Un acercamiento a los derivados denominales en -ble en castellano medieval". En «Llaneza». Estudios dedicados al profesor Juan Gutiérrez Cuadrado, editado por María Bargalló Escrivà y María Pilar Garcés Gómez, 69-80. A Coruña: Universidade da Coruña.

" Grandgent, Charles.1907/2009. An introduction to Vulgar Latin. Richmond/Surrey: Tiger Xenophon.

» Grevisse, Maurice y André Goosse. 1936/2016. Le bon usage. Bruxelles: De Boeck Supérieur.

" Hanssen, Federico. 1889. "Die Aktivbedeutung der Adjektiva auf -bilis im archaischen Latein”. Philologus 47: 274-90.

» Hoad, Terry (ed.). 1986. The concise Oxford dictionary of English etymology. Oxford/New York: Oxford University Press.

" Hopper, Paul y Sandra Thompson. 1980. "Transitivity in grammar and discourse”. Language 56, 2: 251-299.

"Jesperson, Otto. 1924. The philosophy of grammar. London: Allen and Unwin.

"Kabatek, Johannes, 2005, “Tradiciones discursivas y cambio lingüístico”. Lexis 2: 151-177.

»Lang, Mervyn. 2002. Formación de palabras en español. Morfología derivativa productiva en el léxico moderno. Madrid: Cátedra.

"Lapesa, Rafael. 1981. Historia de la lengua española. Madrid: Gredos.

» Leumann, Manu. 1917. Die lateinischen Adjektiva auf-lis. Straßburg: Trübner.

》 Leumann, Manu. 1977. Lateinische Laut- und Formenlehre. München: Beck.

» Löfstedt, Einar. 1959. Late latin. Oslo: Aschehoug.

" Lüdtke, Jens. 2011. La formación de palabras en las lenguas románicas: su semántica en diacronía y sincronía. Ciudad de México: El Colegio de México.

" Lyons, John. 1977. Semantics. Cambridge: Cambridge University Press, 2 vols.

» Menéndez Pidal, Ramón. 1929. Orígenes del español. 1. Estado lingüístico de la Península Ibérica hasta el siglo XI. Madrid: Espasa-Calpe.

» Meyer-Lübke, Wilhelm. 1890-1906/1972. Grammatik der Romanischen Sprachen. Hildesheim: Georg Olms Verlag, 4 vols.

» Miranda, Alberto. 1994. La formación de palabras en español. Salamanca: Colegio de España. 
"Nebrija, Antonio. 1492/2011. Gramática sobre la lengua castellana, ed. de Carmen Lozano. Madrid: Galaxia Gutenberg.

»Perseus: Crane Gregory (ed.) (online), Perseus digital library. <http://www.perseus.tufts. edu/hopper/> [08/2021].

"Pharies, David. 2002. Diccionario etimológico de los sufjos españoles. Madrid. Gredos.

» RAE y ASALE. 2009. Nueva gramática de la lengua española. Madrid: Espasa, 2 vols.

"Rainer, Franz. 1993. Spanische Wortbildungslehre. Tübingen: Niemeyer.

»Rainer, Franz. 1999. “La derivación adjetival”. En Gramática descriptiva de la lengua española, dirigido por Ignacio Bosque y Violeta Demonte, vol. III: 4595-4644. Madrid: Espasa.

" Rifón, Antonio. 2021. "Suffix evolution in derivation: Four cases from Latin to Spanish". En The Routledge handbook of Spanish morphology, editado por Antonio Fábregas et al., 222-235. London: Routledge.

"Schwegler, Armin. 1990. Analyticity and syntheticity: A diachronic perspective with special reference to Romance languages. Berlin/New York: Mouton de Gruyter.

"Väänänen, Veikko. 1959. Le Latin vulgaire des inscriptions pompéiennes. Berlin: AkademieVerl.

»Väänänen, Veikko. 1985. Introducción al latín vulgar. Madrid: Gredos.

»Val Álvaro, José Francisco. 1981. “Los derivados sufijales en-ble en español”. Revista de Filología Española 61: 185-198.

》Zieliński, Andrzej. 2013. "Evolución semántico-sintáctica del sufijo superlativo «-ísimo» en castellano". Romanica Cracoviensia 13: 105-15.

"Zieliński, Andrzej. 2015. "«Hallé un río grandísimo, digo muy grande»: historia y comportamiento del sufijo "-ísimo" en español”. En Actas del IX Congreso Internacional de Historia de la Lengua Española (Cádiz, 2012), editado por José María García Martín et al., vol. I: 1157-1170. Madrid/ Frankfurt am Main: Iberoamericana/Vervuert.

"Zieliński, Andrzej y Rosa María Espinosa Elorza. 2018. La modalidad dinámica en la historia del español. Frankfurt am Main: Peter Lang. 